\title{
Analysis of Pull-Out Behaviour of Straight and Hooked End Steel Fibres
}

\author{
Sadoon Abdallah, David W. A. Rees \\ College of Engineering, Design and Physical Sciences, Brunel University London Uxbridge, London, UK \\ Email: sadoon.abdallah@brunel.ac.uk, David.ress@brunel.ac.uk
}

How to cite this paper: Abdallah, S. and Rees, D.W.A. (2019) Analysis of Pull-Out Behaviour of Straight and Hooked End Steel Fibres. Engineering, 11, 332-341.

https://doi.org/10.4236/eng.2019.116025

Received: March 26, 2019

Accepted: June 25, 2019

Published: June 28, 2019

Copyright (๑) 2019 by author(s) and Scientific Research Publishing Inc. This work is licensed under the Creative Commons Attribution International License (CC BY 4.0).

http://creativecommons.org/licenses/by/4.0/

\begin{abstract}
The effective utilisation of steel fibre reinforced concrete (SFRC) requires in-depth and detailed understanding of bonding mechanisms governing the tensile behaviour. In response to this demand, this study presents an empirical description of the axial force required to pull out a hooked end steel fibre from a cementitious matrix. It is based upon consistent experimental tests that show the force versus displacement plot is formed from a sequence of events in which partial and full debonding at the interface is followed by bending of the hook knee to raise the force to its maximum. A loss of peak force occurs with the reversed plasticity involved in a full straightening of the fibre that precedes the rapid sliding to its full removal under a falling force. The stages are assembled in the said order with a piecewise connection between linear segments and a curve of exponential decay. A power law can be introduced to describe the knee bending stage if preferred. The normalised co-ordinates were adopted for the simple mathematical discontinuous function of the full pull-out process. Normalising force and displacement for hooked fibre is based upon the maximum values found for straight fibre pull out. This would apply to an overall embedded length of unity and a unit peak force for a full debonding of straight fibre in similar materials. For hooked fibre the normalised co-ordinates given refer to the initiation and duration of each event to be tabulated at fractions of the embedded length with multiples of that force. Such predictions are seen to be in good agreement with average pull-out response curves.
\end{abstract}

\section{Keywords}

Pull-Out Behaviour, Plastic Hinge, Mechanical Anchorage, Hooked End Fibre, Analytical Formulation 


\section{Introduction}

The development of steel fibre reinforced concrete (SFRC) marks a huge step forwards in building materials and construction technology, which is indispensable in the modern structural applications [1]. The intention of adding short randomized reinforcing steel fibres to cementitious materials is to improve their tensile behaviour by resisting the cracking propagations [2]. To what extent the tensile response of SFRC could be improved depends upon several parameters. Fibre characteristics, fibre shape, fibre content, fibre distribution and orientation with respect to load direction, the quality of the cementitious matrix surrounding the fibre and bond mechanisms all affect the tensile response together [3]. Of these, the interfacial bond characteristics between fibre and matrix play a crucial role in controlling the overall behaviour of the composite. Pull-out testing of straight and hooked end fibres embedded in a concrete matrix has accompanied this relatively new method of reinforcement [4]. Short fibre, randomly distributed offers resistance to tensile failure in concrete structures quite apart from the traditional reinforcing bars for beams. Fibre orientations ensure that some align with the principal tensile stress when the loading is complex and variable. Effective fibres resist tension through their bonding with the matrix and anchorage within their geometry [5]. Stress transfer and hinge plasticity are strengthening properties provided by fibres within a cracked matrix. The testing helps to understand mechanisms involved by showing the consistent sequence of events in which fibre pull-out occurs. There have been theories proposed of the force required to displace both straight and hooked fibres but the multi-stage, multi-variable process can defy a purely theoretical description. However, the consistency in the order of each stage promotes practical empirical description of the whole process within a discontinuous function. It will be shown how an averaged experimental pull-out curve lends itself initially to a connection of linear segments describing bond breakdown and hook straightening. Thereafter, an exponential function describes the decaying force for straight fibre release. The utility of this model adopts normalised co-ordinates that admit the strengths within the composite material and a specific fibre geometry with a unit embedded (normalised) length. Stages of pull-out are associated with simple straight line equations with gradient stiffness and critical point intersections. The short load plateaus that appear with the straightening of fibre knees identify with the virtual work theory of plastic collapse. Some attempts to model the effect of fibre geometry on the pull-out response which have also been made in recent years. However, these models are restricted to a set of material properties and experimental boundary conditions. Their ability to provide an effective understanding of the bonding mechanisms is limited due to involving large number of parameters. Therefore, an accurate prediction of the pull-out behaviour of the deformed fibres is of paramount importance for the structural design of SFRC elements. Yet, suitable and reliable predictions of the pull-out behaviour of hooked end steel fibres are still needed. This study aims to provide simple and conceptual method to predict the bonding mechanisms governing the pullout responses of straight and hooked end fibres. 


\section{Experimental Study}

\subsection{Samples Preparation and Test Setup}

The pull-out tests on single steel fibre were performed using the cube of $(100 \times$ $100 \times 100 \mathrm{~mm}$ ). In each specimen, one steel fibre was placed carefully in a hole made through the bottom of moulds. The embedded length $\left(L_{\mathrm{E}}\right)$ was one half of the fibre length (i.e. $30 \mathrm{~mm})$. For compressive strength test three cubes of $(100 \times$ $100 \times 100 \mathrm{~mm}$ ) were prepared for each mixture. The mixtures were prepared using a laboratory Pan mixer. During specimen fabrication, the components were firstly dry mixed for approximately $1 \mathrm{~min}$ followed by the addition of water and superplasticizer to the dry mixture. The mixture was then mixed for $11 \mathrm{~min}$. After casting and vibration, the specimens were covered with a thin polyethylene film and left for $24 \mathrm{~h}$ at room temperature. Then specimens were removed from their moulds and cured for a further 28 days in the conditioning chamber $\left(20^{\circ} \mathrm{C}\right.$ $\left.\pm 2^{\circ} \mathrm{C}, 96 \% \pm 4 \% \mathrm{RH}\right)$. For both compressive and pull-out specimens, the test was carried out at an age of $30 \pm 2$ days and the average value of six specimens was adopted.

The pull-out tests were performed using a specially designed grip system, as illustrated in Figure 1, which was attached to an Instron 5584 universal testing machine. The grips were designed such that the forces applied to the fibre provided a true reflection of the real situation experienced by fibres bridging a crack. The body of the gripping system was machined in a lathe using mild steel



Figure 1. Test setup. 
and had a tapered end to allow the insertion of four M4 grub screws (Figure 1). These were then tightened around the steel fibre to an equal torque for an even distribution of gripping pressure to minimise the deformation of the fibre ends and avoid breakage at the tip. Two linear variable differential transformer (LVDT) transducers were used to measure the distance travelled by the steel fibre relative to the concrete face during testing (i.e. the pull-out distance). They were held in place using aluminium sleeves on either side of the main grip body (Figure 1). The LVDT's had ball bearings at the tips to allow for accurate readings on the face of the samples. The sample was secured to the Instron base using clamps with riser blocks and M16 studs. The specimen was positioned on a brass round disc to remove any discrepancies in the sample base and allow for distortion. In all pull-out tests, a displacement rate of $10 \mathrm{~mm} / \mathrm{s}$ was adopted.

\subsection{Pull-Out Mechanisms of Straight Fibres}

It can be seen from Figure 2(A) that the pull-out behaviour of straight fibre involves a combination of two different mechanisms: de-bonding (stages $(o-a)$ and $(a-b))$ and frictional pull-out (stage $(b-c))$. Here, the de-bonding arising from cracking within and along the interfacial transition zone (ITZ) is followed by fibre pull-out under frictional resistance only. Figure 3(A) shows the average pull-out-slip curve of straight fibre embedded in a concrete matrix up to half fibre length i.e. $30 \mathrm{~mm}$. The mix proportions, specimen's preparation and testing method are given in [6].

The pull-out-slip response of straight fibres is characterized by a rapid increase in pull-out load $(a-b)$ followed an equally rapid drop at $(b)$, indicating that the fibre de-bonds suddenly from the concrete (Figure 2(A)). Thereafter, the pull-out load from $(b-c)$ continues to fall with increasing slip. Hence, the straight fibres bond is made up only of chemical adhesion and static friction with no mechanical interlock. So, once these mechanisms are overcome, the fibre slips with a diminishing pull-out force necessary to overcome kinetic friction in the remaining contact zone (Figure $3(\mathrm{~A})$ ).

\subsection{Pull-Out Mechanisms of Hooked End Fibres}

Initial mechanisms (stages: $o-a, a-b$ and $b-c$ ) governing the pull-out behaviour of hooked end fibres are similar to those measured for straight fibres (i.e. de-bonding, followed by frictional pull-out). This means that theoretical expressions apply to these from the initiation of elastic bond failure at (a) and its completion at $(b)$ for both fibres. Here, however, the frictional pull-out (stage $g-h$ ) is preceded by mechanical interlocking stages $(c-d)$ to $(f-g)$. To release $(c-d)$ to $(f-g)$ both curvatures must straighten within plastic hinges ( $\mathrm{PH} 1$ and $\mathrm{PH} 2)$. Thus, the fibre hook must undergo considerable plastic deformation, resulting in a substantial increase and maximum pull-out load at c (Figure 3(B)). This sequence of events in the pull-out process is shown diagrammatically in Figure 2(B). Beyond its maximum, the pull-out load starts to decrease due to the progressive mobilization and entrance of $\mathrm{PH} 1$ into the straight part of the channel. 
(o-a) Partly debonded

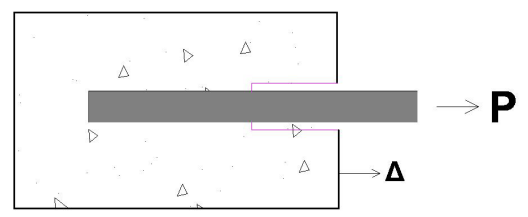

(a-b) Fully debonded

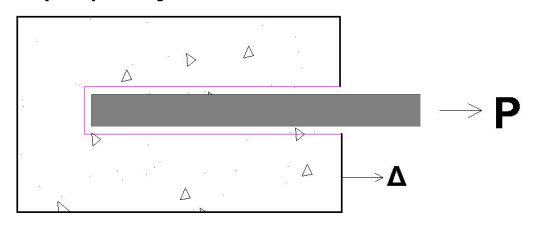

(b-c) Pull-out

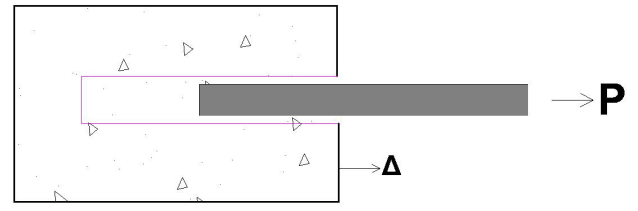

(A)

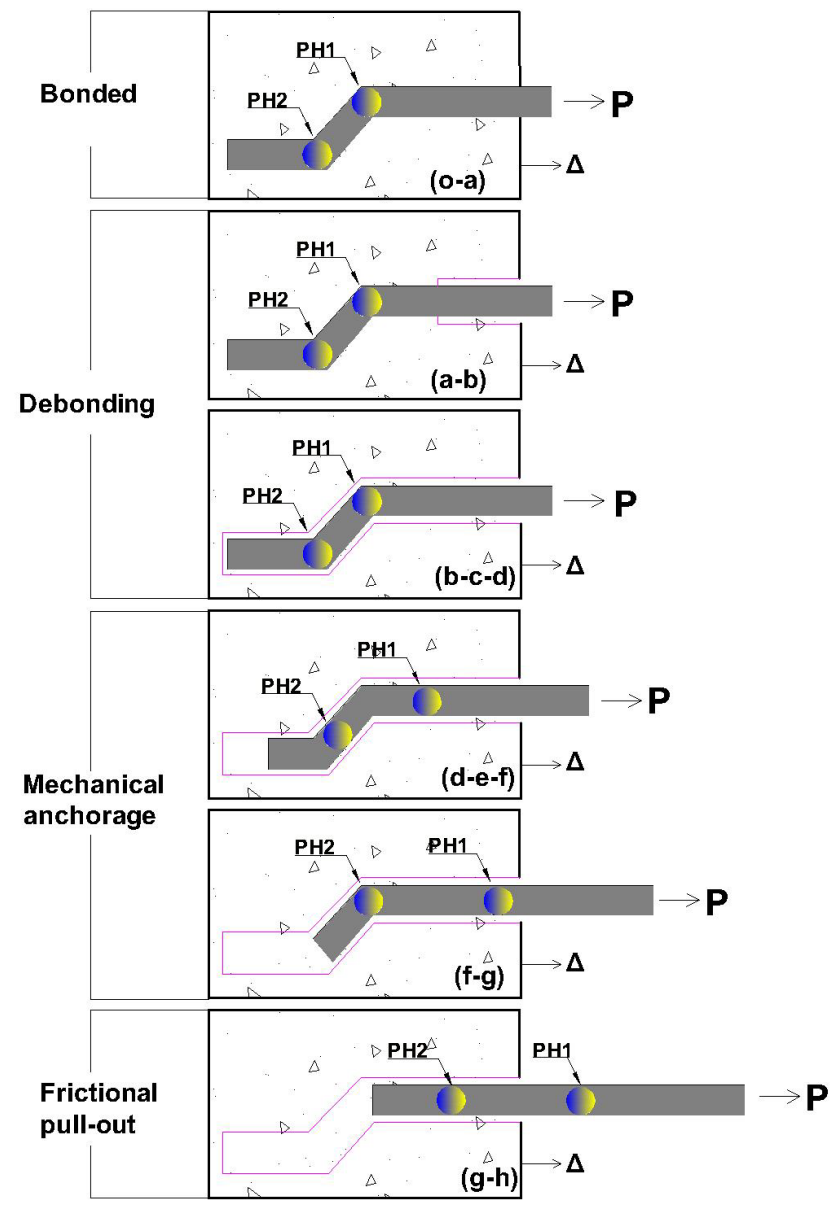

(B)

Figure 2. Schematic diagram of pull-out behaviour: (A) Straight fibre and (B) Hooked end fibre. 


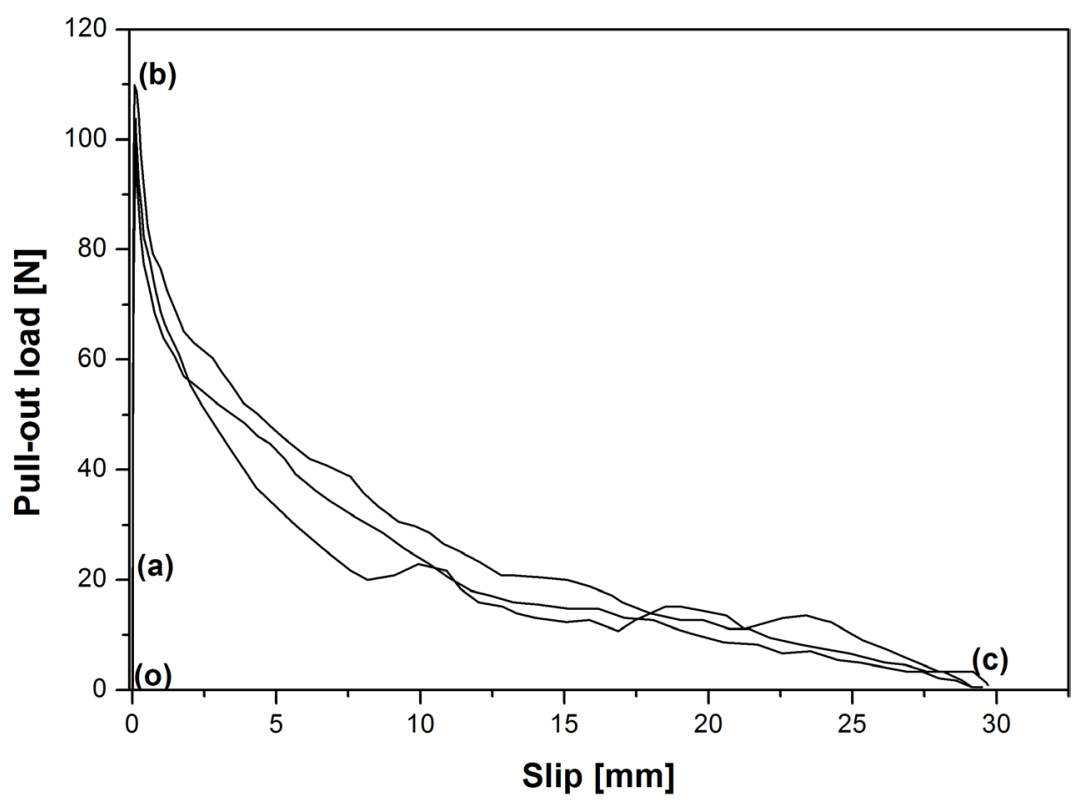

(A)

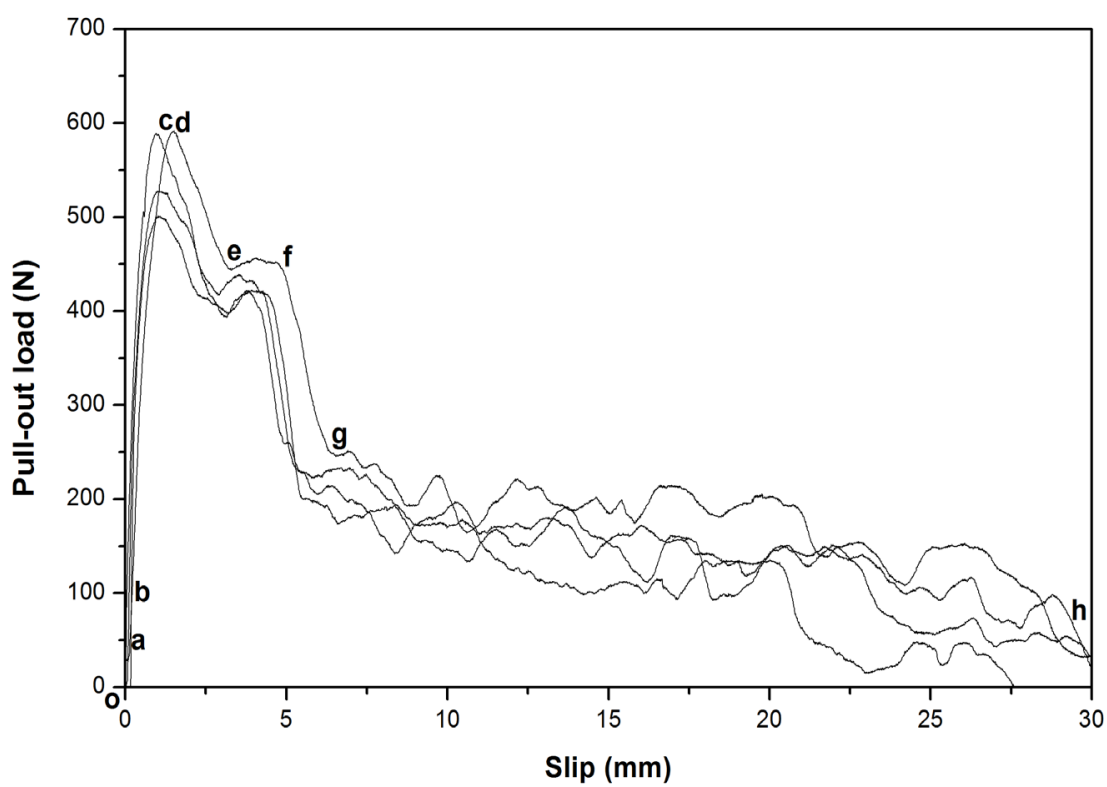

(B)

Figure 3. Pull-out load-slip curves: (A) Straight fibre and (B) Hooked end fibre.

When PH1 has straightened, the wire moves into the straight part of the channel. Then moving and straightening of $\mathrm{PH} 2$ results in a slight decrease in pull-out load (stage $d$-e). Once both $\mathrm{PH} 1$ and $\mathrm{PH} 2$ are completely deformed and straightened, the pull-out load need only overcome kinetic frictional resistance as for a straight fibre (stage $g-h$ ). This phase prevails until the whole fibre is completely removed from the matrix.

\section{Empirical Formulation}

The schematic representation of the multi-stage process for straight and double- 
bend fibres is shown in Figure 4(A) and Figure 4(B), respectively. Experiment [7] suggests that the normalised co-ordinates permit any fibre/cementitious material combination. They refer to the maximum force $\left(P_{b}\right)$ at $(b)$ in a straight fibre of unit embedded length at $(h)[8]$. In Figure 4, $P$ represents the pull-out force and $\Delta$ is displacement in which the corresponding ratios $P / P_{b}$ and $\Delta_{\mathrm{x}} / \Delta_{h}$ are relative to straight fibre pull out.

The pull-out stage equations adopted for a hooked end, high tensile steel fibre and high strength concrete are given in Table 1 in which $x$ and $y$ are the normalised displacement and pull-out force, respectively.

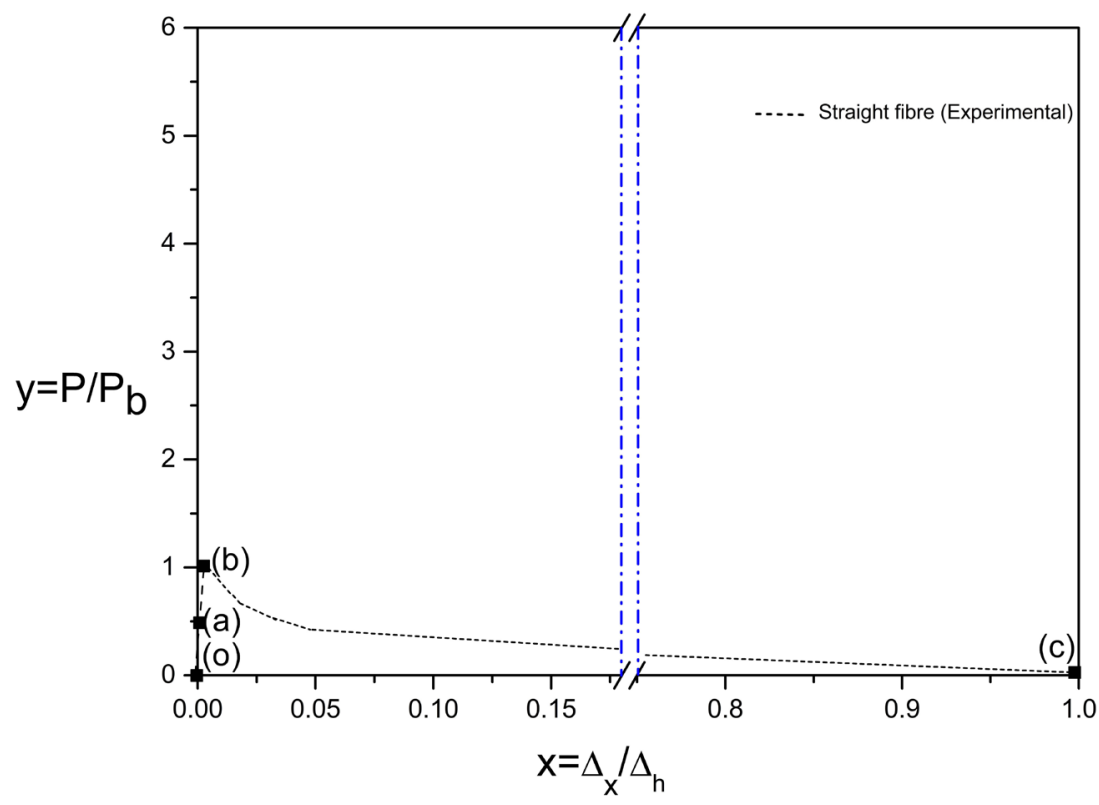

(A)

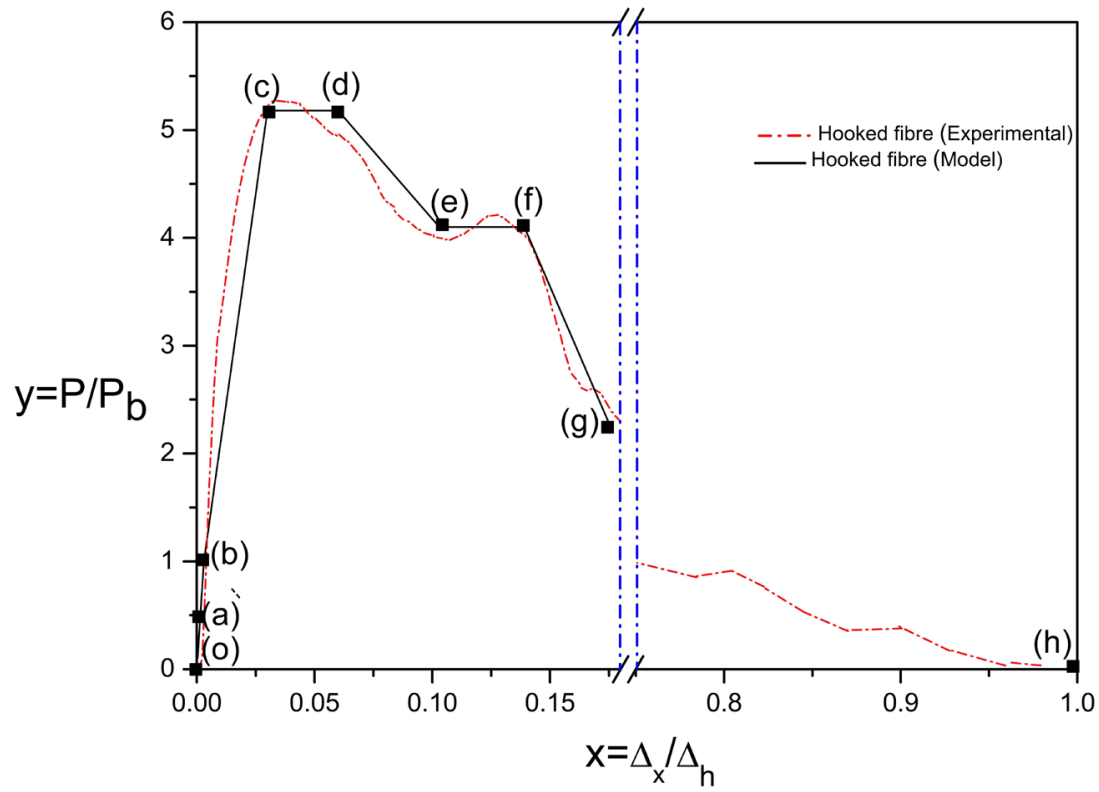

(B)

Figure 4. Normalised schematic pull-out plot: (A) Straight fibre and (B) Hooked end fibre. 
Table 1. Main stages of pull-out process of hooked-end fibre.

\begin{tabular}{|c|c|c|}
\hline Stage & Description & Equation \\
\hline$o-a$ & $\begin{array}{l}\text { When a pull-out load } y \leq y_{a} \text {, the fibre remain perfectly bonded to the matrix and the } \\
\text { interface is kept in an elastic bond condition. }\end{array}$ & $y=m x, m=y_{a} / x_{a} \quad\left(0 \leq x \leq x_{a}\right)$ \\
\hline$a-b$ & $\begin{array}{l}\text { When } y>y_{a} \text {, a part of the fibre is still fully bonded to the matrix while the remaining } \\
\text { part is de-bonded. }\end{array}$ & $\begin{array}{c}y=m x+c, m=\frac{1-y_{a}}{x_{b}-x_{a}}, c=1-m x_{b} \\
\left(x_{a} \leq x \leq x_{b}\right)\end{array}$ \\
\hline$b-c$ & $\begin{array}{l}\text { Once interface de-bonding is completed at }(b) \text {, the horizontal portion of the fibre must } \\
\text { overcome kinetic friction as the hooked end of the fibre undergoes reverse bending. }\end{array}$ & $\begin{array}{c}y=m x+c, m=\frac{y_{c}-1}{x_{c}-x_{b}} \frac{y_{2}-1}{x_{2}-1}, c=1-x_{b} \\
\left(x_{b} \leq x \leq x_{c}\right)\end{array}$ \\
\hline$c-d$ & $\begin{array}{l}\text { Due to the cold work from both plastic hinges ( } \mathrm{PH} 1 \text { and } \mathrm{PH} 2) \text {, the pull-out load remains } \\
\text { until the fibre pulled by an additional distance }\left(x_{d}-x_{c}\right) \text {. }\end{array}$ & $y=y_{c}=y_{d} \quad\left(x_{c} \leq x \leq x_{d}\right)$ \\
\hline$d-e$ & $\begin{array}{l}\text { When PH1 has straightened, the fibre moves into the straight part of the channel. Then } \\
\text { moving and straightening of } \mathrm{PH} 2 \text { results in a slight decrease in pull-out load. }\end{array}$ & $\begin{array}{c}y=m x+c, m=\frac{y_{d}-y_{e}}{x_{d}-x_{e}}, c=y_{d}-m x_{d} \\
\left(x_{d} \leq x \leq x_{e}\right)\end{array}$ \\
\hline$e-f$ & At this stage, the load remains until the fibre is pulled by an additional distance $\left(x_{f}-x_{e}\right)$. & $y=y_{e}=y_{f} \quad\left(x_{e} \leq x \leq x_{f}\right)$ \\
\hline$f-g$ & $\begin{array}{l}\text { Once both } \mathrm{PH} 1 \text { and } \mathrm{PH} 2 \text { are completely deformed and straightened, the load drops to }(g) \\
\text { with no plastic hinges active. }\end{array}$ & $\begin{array}{c}y=m x+c, m=\frac{y_{f}-y_{g}}{x_{f}-x_{g}}, c=y_{f}-m x_{f} \\
\left(x_{f} \leq x \leq x_{g}\right)\end{array}$ \\
\hline$g-h$ & $\begin{array}{l}\text { At this stage, the pull-out load need only overcome kinetic frictional resistance as for a } \\
\text { straight fibre. This phase prevails until the whole fibre is completely removed from the } \\
\text { matrix at }(h) \text {. }\end{array}$ & $y=y_{g}\left[1-e^{\left(x_{g}-1\right)}\right] \quad\left(x_{g} \leq x \leq x_{h}\right)$ \\
\hline
\end{tabular}

Note 1: For stage $(a-b)$ : A straight fibre pull-out load $P_{b}$ is derived from the normalised ordinate $y_{b}$ for two straight intersecting lines that lie within ranges $(o-a)$ and $(a-b)$ as shown in Figure 3. That is, from Figure 3:

$$
y_{b}=m_{o a} x_{a}+m_{a b}\left(x_{b}-x_{a}\right)=\left(m_{o a}-m_{a b}\right) x_{a}+m_{a b} x_{b}
$$

Note 2: For stage $(b-c)$ : Should a power law curve be preferred this is written as:

$$
\frac{y}{y_{b}}=\left(\frac{x}{x_{b}}\right)^{n}
$$

where debonding co-ordinate $\left(x_{b}, 1\right)$ appear from Note 1 above and $n \leq 1$ is a reversed bending index suited to the material combination as shown in Figure 4.

Note 3: The plateau load attained for region $(b-c)$ is provided by the virtual work principle [8]. This principle refers the two hinges plastic bending to the collapse loading at $(c-d)$ given in normalised co-ordinates as the difference:

$$
y_{c}-y_{b}
$$

Note 4: Similar to Note 3 the plateau load for given of refers to single hinge plastic bending to attain full straightening under a reduced collapse loading condition given by the co-ordinate reduction: $y_{d}-y_{e}$. 


\section{Conclusion}

A schematic pull-out plot identifies with linear segments within each stage of fibre resistance. Bond breakdown occurs in two stages with an embedded straight fibre attaining a maximum force at full debonding. There follows an exponential decay as the fibre to retracted with diminishing resistance [9]. Hooked fibre promotes an intermediate deformation stage. Here the anchorage provided by a double bend hook raises the force to a greater level necessary for it to be withdrawn. During straightening of the hook's opposing bends the pull out force versus deflection plot appears as a plateau under the greatest force attained. Normalised co-ordinates used with a hooked fibre correspond to a unit embedded length of fibre and a relative force ratio to straight fibre to enable their conversion to the force and displacement measured in a test. Tabulated co-ordinates given for each stage of fibre resistance show a maximum force ratio of five with pull-out less than $10 \%$ of fibre length. Thereafter the greater part of the normalised plot is consumed in retracting a straightened fibre under a diminishing resistance which commences consistently at a force ratio of unity. The empirical discontinuous function for the whole of pull-out associates regions conveniently between intersections of linear segments. These connect with an exponential for decay in a single constant. The simplification adopted affords a library of co-ordinates for practical applications in various material combinations.

\section{Acknowledgements}

The first author is grateful for the financial support provided by the Ministry of Higher Education and Scientific Research of the Iraqi Government.

\section{Conflicts of Interest}

The authors declare that no conflicts of interest have arisen from the publication of any of the material presented in this paper.

\section{References}

[1] Panda, B., Chandra Paul, S. and Jen Tan, M. (2017) Anisotropic Mechanical Performance of 3D Printed Fiber Reinforced Sustainable Construction Material. Materials Letters, 209, 146-149. https://doi.org/10.1016/j.matlet.2017.07.123

[2] Yan, L., Xing, Y., Zhang, J. and Li, J. (2013) High-Temperature Mechanical Properties and Microscopic Analysis of Nano-Silica Steel Fibre RC. Magazine of Concrete Research, 65, 1472-1479. https://doi.org/10.1680/macr.13.00143

[3] Tadepalli, P.R., Mo, Y. and Hsu, T.T. (2013) Mechanical Properties of Steel Fibre Concrete. Magazine of Concrete Research, 65, 462-474. https://doi.org/10.1680/macr.12.00077

[4] Abdallah, S., Fan, M. and Cashell, K.A. (2017) Pull-Out Behaviour of Straight and Hooked-End Steel Fibres under Elevated Temperatures. Cement and Concrete Research, 95, 132-140. https://doi.org/10.1016/j.cemconres.2017.02.010

[5] Abdallah, S., Fan, M. and Cashell, K.A. (2017) Bond-Slip Behaviour of Steel Fibres in Concrete after Exposure to Elevated Temperatures. Construction and Building Materials, 140, 542-551. https://doi.org/10.1016/j.conbuildmat.2017.02.148 
[6] Abdallah, S. and Fan, M. (2017) Anchorage Mechanisms of Novel Geometrical Hooked-End Steel Fibres. Materials and Structures, 50, 139. https://doi.org/10.1617/s11527-016-0991-5

[7] Alwan, J.M., Naaman, A.E. and Guerrero, P. (1999) Effect of Mechanical Clamping on the Pull-Out Response of Hooked Steel Fibers Embedded in Cementitious Matrices. Concrete Science and Engineering, 1, 15-25.

[8] Naaman, A.E., Namur, G.G., Alwan, J.M. and Najm, H.S. (1991) Fiber Pullout and Bond Slip. I: Analytical Study. Journal of Structural Engineering, 117, 2769-2790. https://doi.org/10.1061/(ASCE)0733-9445(1991)117:9(2769)

[9] Abdallah, S., Fan, M. and Rees, D.W. (2018) Bonding Mechanisms and Strength of Steel Fiber-Reinforced Cementitious Composites: Overview. Journal of Materials in Civil Engineering, 30, Article ID: 04018001.

https://doi.org/10.1061/(ASCE)MT.1943-5533.0002154 